\title{
La industria cinematográfica en la era digital. Diferentes conceptualizaciones y nuevas oportunidades para
}

el creador

The film industry in the digital era. Different conceptualisations and new opportunities for the creator

Mónica López Golán, Pontificia Universidad Católica de El Ecuador - mlopezgol@gmail.com

Abstract

Digitization,asbasic conditionfor technologyandmediaconvergenceis a processwhich has led tomany changesthat occurin different directionsin the bosom ofthe film industry.Its complexityand the rapid growthof its developmentgenerateuncertaintiesin the economic, socialandtechnological levelin thesector.Thecinemahas been forcedtoadapt to new markets and support different than traditional. Theemergence of the Internethas led tothe relocation ofthis medium, intonew forms of expressionandnew consumer habits. Finally, technological reconversionbringsa new economicprofitability forthe film industry. Today, there are audiovisual products and services whose value chain lies entirely in the network, from pre-production to consumption. This profitabilitymust be basedon an understanding of the value than users perceivein digital content, which is strategicallypositionedin the productionand distributionforemerging mediaon theWeband mobile devices.

Keywords

Digitization, film industry, Internet, users, economic profitability.

Resumen

La digitalización, como condición de base para la convergencia tecnológica y de medios, es un proceso que ha originado numerosas modificacionesen el seno de la industria cinematográfica.Su complejidad y el rápido crecimiento de su desarrollo generan cambios en el plano económico, social y tecnológico del sector. El cine se ha visto obligado a adaptarse a nuevos mercados y soportes diferentes al tradicional. La aparición de Internet ha derivado en la reubicación de este medio, en nuevas formas de expresión y en nuevos hábitos de consumo. Finalmente, la reconversión tecnológica trae consigo una nueva rentabilidad económica para la industria cinematográfica. Hoy en día existen productos y servicios audiovisuales cuya cadena de valor reside íntegramente en la red, desde la preproducción al consumo. Esta rentabilidad ha deestar basada en la comprensión del valor que los usuarios perciben en loscontenidos digitales, que se posicionan estratégicamente en la produccióny la distribución para medios emergentes en la Weby dispositivos móviles.

Palabras clave

Digitalización, industria cinematográfica, Internet, usuarios, rentabilidad económica.

1. Introducción. 2. Revisión teórica. 3. Método de la Investigación. 4. Resultados y discusión. 5. Conclusiones. 6. Bibliografía. 


\section{Introducción}

El cine siempre ha ocupado un lugar destacado entre los medios de comunicación de masas y, como tal, ha representado una de las principales fuentes de entretenimiento compartida por un público masivo.Su forma de entretenimiento funciona a través de un objeto de comunicación, la película, cuya elaboración requiere enormes esfuerzos creativos de colaboraciones múltiples y cuantiosas inversiones económicas.Por tanto, en la cinematografía se conjugan, "en proporciones similares"(Cuevas, 1999: 40), el factor artístico con el industrial, dando lugar a un producto sui géneris, cuyo resultado de creación artístico-industrial lo hace diferente a los productos de otras actividades económicas.

Su condición ambigua de arte e industria, así como la diversidad en la concurrencia de colaboraciones humanas y técnicas, son factores que dificultan el análisis de la realidad cinematográfica desde una perspectiva económica. Del mismo modo, es importante matizar que el comportamiento del sector es muy diferente dependiendo del contexto en el que se desarrolle. Así, la organización industrial, elcontrol vertical del mercado y la estandarización de los contenidos han convertido alcine norteamericano en una marca de éxito reconocible en cualquier parte delmundo. En contrapartida, ni las diferentes legislaturas ni lasayudas públicas han conseguido corregir los principales defectos de la industriacinematográfica española.

En este trabajo se realizará una aproximación a la industria cinematográfica en un marco estructural de reconversión tecnológica. Se analizarán las transformaciones que, desde el comienzo de la digitalización, se han producido en el ámbito cinematográfico desde el punto de vista de la creación. Observaremos como las innovaciones de las nuevas tecnologías, teniendo en cuenta la naturaleza visual del medio, están dejando su huella más visible en el resultado creativo del producto película. Del mismo modo, veremos como el fenómeno de la digitalización ha alterado el sistema económico de la industria derivando en nuevos modelos de negocio, vías de participación para el usuario y formas de relación entre creadores y consumidores.

\section{Revisión teórica}

El advenimiento de tecnologías como el 3D, la "cultura visual digital" (Darley, 2002) derivada de la estrecha relación entre filme y ordenador, la ubicuidad que define a una industria cuya exhibición no se restringe únicamente a las salas de cine (Harbord en Roig, 2009: 174), la convergencia de medios, el surgimiento de novedosos soportes y, sobre todo, las nuevas formas de consumo demandadas por un público más activo, son factores que han dado lugar a las diferentes conceptualizaciones del cine digital y los nuevos modelos de negocio para el sector.

Para el abordaje de las diferentes conceptualizaciones que se establecen desde el punto de vista de la creación, analizaremos los trabajos de Manovich (2005) o Darley (2002), autores pertenecientes a una corriente que se ha mostrado más interesada por las formas visuales artísticas que emergen con el desarrollo tecnológico. El trabajo de Jenkins (2008), que ha centrado sus investigaciones en la "cultura participativa", será la base para nuestro análisis en relación a las nuevas formas de uso y consumo en el ámbito cinematográfico. Desde el punto de vista de la economía del sector, referenciaremos los trabajos realizados por Jacoste (2004), Cuevas (1999) y Dadek (1962).

Jacoste (2004), basándose (pero matizando) en el análisis económicoque Giannelli elabora de la realidad cinematográfica, hace referencia a un"subsistema económico clásico" al que diferencia de otros dos a los que denomina"subsistemaeconómico nuevo" y "atípico". La estructura del subsistema clásico se edifica sobre tres ramas: producción, distribución y exhibición y su análisis se realiza a partir de la diferenciación de dos grandes áreas, la de producción, en la que tienen cabida las empresas productoras, y la de mercado. En esta última, sobre la clasificación de Giannelli, Jacoste diferencia dos subáreas: oferta (importación, distribución, exportación y exhibición) y demanda (público). Una vez delimitado el campo de la oferta, el autor establece la frontera entra la oferta interior (importación, distribución y exhibición) y la oferta exterior (exportación). La categoría de la demanda está representada por el público.

"La producción, en sentido estricto, abarca desde los primeros planes de un proyecto de película hasta el montaje final de las copias, siendo la parte más aparente y notoria del proceso económico" (Dadek, 1962: 18).En el negocio del cine, afirma Dadek (1962: 26-27), hay un importante intervalo de tiempo desde que finaliza la elaboración del producto hasta la consumación del negocio. Este factor tiempo concentra la labor de la distribuidora como intermediaria entre la producción y la exhibición.En este subsistema económico clásico, se reconoce a las salas de cine como las únicas responsables de que las películas puedan ser consumidas por el gran público.

En el subsistema económico nuevo (Jacoste, 2004), la empresa productora continúa siendo el motor principal de la industria del cine. La diferenciamás destacada con respecto al subsistema clásico es el ensanchamiento delúltimo eslabón de la cadena de la oferta. Por tanto, la exhibición públicadel producto película ya no corre a cargo, exclusivamente, de las salas deexhibición, sino que existen otras posibilidades de consumo por parte delespectador, representadas por la televisión y los videoclubs. Finalmente, este autor hace referencia a un subsistema atípico en el que la exhibición no se hace a través de las salas de cine, sino que éstas son sustituidas por las emisoras de televisión. Además de esta particularidad, "las relaciones entre emisoras de televisión y el público no se producen dentro del marco de un mercado propiamente dicho (mercado de exhibición), donde las prestaciones reales se corresponden o generan unas directas contraprestaciones monetarias" (Jacoste, 2004: 57). En este caso, la contraprestación por parte del público es indirecta.

En nuestra investigación trataremos de descubrir un sistema económico diferente enmarcado en el contexto digital y que contemple aspectos que no figuran en los señalados por Jacoste. Aun así, no se perderán de vista estos trabajos precedentes, porque pese a que no representan la realidad absoluta del momento, siguen siendo fundamentales y nos proporcionarán la base de nuestros razonamientos.

\section{Método de la investigacíon}

En este artículo se recoge un conjunto de reflexiones de carácter teórico fruto de diferentes procesos de investigación empírica desde una óptica cualitativa basada en el análisis de las tendencias cinematográficas en la era digital. El interés de la investigación se dirige hacia la 
comprensión de las diferentes prácticas que surgen en el seno del sector como consecuencia de la llegada de las nuevas tecnologías como elemento clave para el desarrollo del proceso de producción, distribución y exhibición del producto audiovisual.

Analizar diversas experiencias desarrolladas en el ámbito del sector, así como fuentes teóricas que abordan el estudio de estas tendencias, ayudará a una comprensión global, descriptiva e interpretativa del fenómeno de la digitalización en la industria cinematográfica, dando lugar a diferentes conceptualizaciones desde el punto de vista de la creación, de la distribución y de la explotación.

\section{Resultados y discusión}

El desafío digital ha abierto un mundo de posibilidades a los creadores cinematográficos en relación a la producción y postproducción. Del mismo modo, las nuevas tecnologías y las actuales lógicas de la comunicación, brindan a los usuarios la oportunidad de superar su condición de usuarios pasivos para convertirse en productores. Por otro lado, surgen nuevos modelos de gestión de contenidos digitales que muestran especificidades necesitadas de atención desde el punto de vista de la regulación para una eficaz rentabilidad económica.

\subsection{Producción y postproducción en la era digital}

"Dado que, para la mayoría de espectadores y críticos, el cine equivale a contar una historia, los medios informáticos se entienden como algo que llevará al cine a contar sus historias de una manera nueva"(Manovich, 2005: 366). Se está refiriendo Manovich en esta afirmación, a la transformación que el uso del ordenador produce en la narrativa, pero como él mismo afirma, de esta manera se contempla un sólo aspecto, que no es ni esencial ni el único. Son varios los que hay que contemplar.

Roig (2009: 175-176), basándose en las aportaciones de diversos autores, habla de cuatro tipos de cine digital dentro del áreade la producción y postproducción:

- $\quad$ Cine registrado en soporte de vídeo digital.

- $\quad$ Cinene postproducido utilizando herramientas digitales de retoque de las imágenes originales.

- Cine con integración de imágenes reales con imágenes digitales por ordenador durante el proceso de postproducción.

- Cine basado íntegramente en la generación de imágenes digitales por ordenador.

Según Manovich (2005), parte de estas nuevas herramientas de postproducción han hecho que la imagen digital se aproxime mucho más a la pintura que a la fotografía o al cine. Las posibilidades plásticas de composición y edición heredadas de la postproducción tradicional han aumentado hasta el punto de introducir la capacidad, no sólo de la manipulación digital de la imagen, sino también de su generación a través de la síntesis digital (Darley, 2002: 40-41). Por tanto, las herramientas de postproducción de la era digitalponderan la condición virtual de la imagen digital. La posibilidad de su inagotable manipulación puede hacer, incluso, que se pierda la conexión con el referente.

Tanto el registro como la postproducción digital han abierto nuevas posibilidades estéticas que enriquecen la creatividad, además de ofrecerla posibilidad a pequeñas productoras o creativos independientes de acceder a un mercado copado por las majors norteamericanas. Del mismo modo, y también dentro de la fase de producción, surgen prácticas colaborativas como el crowdfunding. En esta estrategia, el creador, utilizando Internet como herramienta de operaciones, abre a la participación ciudadana la captación de fondos para el desarrollo de un proyecto audiovisual. Por tanto, con la llegada de este nuevo medio, también las puertas para la financiación se han ensanchado.

\subsection{Distribución y explotación del producto audiovisual en la era digital}

El potencial de las tecnologías digitales permite, además de producir y financiar una película con la intervención de procedimientos digitales, ampliar y modificar los tradicionales canales para su explotación y distribución.

La digitalización genera grandes cambios en la distribución de las películas, quizás, uno de los más importantes sea lacapacidad de la reducción de los costes. Desde el punto de vistafuncional, la distribución ha sido la fase menos vinculada a la tecnología. Supapel de intermediario entre las productoras y los responsables de lasventanas de exhibición, como apuntaban los subsistemas económicos descritos en apartado teórico, se limita a seleccionar el contenido y venderlo. Esto le ha permitido mantener el control en la etapa analógica sobre la que se ha erigido la estructura del cine hasta el momento. Sin embargo, la digitalización, que ha proporcionado la creación de plataformas Web para la distribución de películas online, le está obligando a rediseñar estrategias que le permitan mantener su hegemonía.

En cuanto a la exhibición, estamos viviendo un momento en el que la digitalización se está apoderando de las salas cinematográficas, dominadas hasta hace pocos años por la tecnología de 35 milímetros. En España, el 92,4\% de los cines poseen proyector digital gracias al incremento de 484 pantallas en el último año (AIMC, 2015). Por tanto, desde este punto de vista, el proceso de digitalización está a punto de completarse.

Pese a que investigaciones demuestran continuamente, y la taquilla así lo ratifica, que el visionado en sala sigue siendo la experiencia más atractiva para la mayor parte del público, Internet ha favorecido un nuevo modelo de comercio digital y la proliferación de otras formas de visionado. Roig (2009: 180-181), atendiendo a esta dimensión del cine en la era digital, y basándose en el análisis que Janet Wasco (2002) hace de las potencialidades que las nuevas tecnologías adjudican al negocio, realiza la siguiente clasificación:

1. Video bajo demanda (VoD): herramienta de distribución que permite al usuario, de manera personalizada, el acceso a películas, a otros productos audiovisuales e incluso a materiales promocionales. A su vez, dentro de este sistema, los autores diferencian tres modalidades: 
- Distribución a través de Internet. La mayor capacidad del procesamiento de los ordenadores, el aumento del ancho de banda, las tecnologías inalámbricas y la bajada de precios por parte de la industria electrónica, ha facilitado este tipo de distribución. Estos factores han contribuido a la estructuración de nuevos modelos de negocio y la adaptación del modelo tradicional de ventanas de exhibición, que han aumentado con la aparición de nuevos soportes. Teniendo en cuenta que los dos tipos de consumo a través de la red son el streaming y el download, diferenciaremos dentro de esta modalidad, y será una de nuestras aportaciones para estructurar de manera más clara la situación actual, entre dos modelos diferentes de distribución online:

- El modelo asociado a dispositivos de reproducción. A día de hoy, este modelo engloba las experiencias más exitosas. En Estados Unidos, el mercado más desarrollado, ha triunfado el sistema de descarga de películas para venta y alquiler de iTunes Store de Apple, con posibilidad de visionado, o bien a través de los diferentes dispositivos móviles o por televisión a través de Apple TV.

- El modelo asociado a las plataformas Web. Esta modalidad engloba servicios diferentes como la descarga y venta permanente de películas, el alquiler, la suscripción a servicios de descarga o streaming (SVoD) o estos mismos soportados por publicidad (FVoD). En este caso, el dominio está representado por las plataformas ligadas a las majors y a aquellas que han actuado como disruptor del sistema tradicional (Izquierdo, 2011).

- Internet como herramienta de marketing de los productos. La red se convierte en una herramienta promocional más, incluyendo la posibilidad del marketing personalizado, para obtener información sobre los gustos y las preferencias de las audiencias.

- Distribución a través de televisión digital interactiva. A través de plataformas de difusión por ADSL o la TDT de pago se puede desarrollar el potencial de esta forma de distribución.

2. Cines electrónicos o digitales: las principales contribuciones de la exhibición digital están representadas por el e-cinema, d-cinema y por las proyecciones en $3 \mathrm{D}$.

\subsection{Nuevas rentabilidades económicas para la industria cinematográfica en la era digital}

Teniendo en cuenta las nuevas posibilidades de producción, postproducción, distribución y exhibición que las nuevas tecnologías ofrecen a la industria cinematográfica en la era digital, y que acabamos de analizar, hemos añadió a los subsistemas económicos desarrollados por Jacoste, el subsistema económico cinematográfico digital. A través de la explicación del mismo, observaremos como el nuevo escenario del sector, favorecido por Internet como factor primordial, viene acompañado de nuevos agentes que se han unido a la cadena de valor de la industria, dando lugar a nuevos modelos de negocio.

\section{Subsistema económico cinematográfico digital}

Todavía no existe ni una estrategia digital ni un único modelo queconduzca a toda la industria hacia una economía digital global. Sinembargo, a sabiendas de que el negocio digital no ha desarrollado todo supotencial, y que, probablemente no lo haga hasta que el proceso industrialy la explotación comercial vayan a la par de lo que demanda elconsumidor, hemos considerado necesario referirnos a un ámbito económico quecontemple, puesto que los anteriores no lo hacen, Internet como nuevocanal de explotación. Esta consideración contribuirá a acercarnos más a larealidad económica actual de esta industria cinematográfica.

En los últimos años hemos sido testigos de los constantes impulsos a latecnología digital, pero sin duda, el más revolucionario ha estadorepresentado por Internet. Este nuevo medio ha cambiado la relación entreel público y el entretenimiento, sobre todo, entre las nuevas generaciones, cuyos patrones de consumo están relacionadoscon el acceso a contenidos a través de tecnologías de bajo coste comomóviles, ordenadores 0 , más recientemente,tablets.

La abundancia de contenidos y su ubicuidad, fácilmente accesiblesa través de Internet, y los costes a la baja de esta tecnología, han hechoque el usuario encuentre alternativas más satisfactorias a través de estemedio que en el mercado tradicional. Esta evolución del comportamientode las nuevas generaciones de consumidores es la que está dirigiendo elcambio en lo que a las vías de explotación se refiere. Pero, a pesar de lagran demanda generada por el público y las ventajas que este canal ofrece, la industria (y el clima financiero conservador al que obliga la crisis)no se lanza a evaluar las muchas posibilidades que ofrece esta tecnologíaal sector.

La industria incorpora elementos digitales al modelo tradicional perono admite la necesidad de una estrategia digital en condiciones. Ante la democratización que permite Internet, les cuesta asumir que puede perder eldominio empresarial. Esto conduce a la imposición de restricciones alconsumidor como los desfases de estreno, algo incomprensible ante lasposibilidades de satisfacer la demanda que tiene la tecnología actual.

Además, algunas voces expertasseñalan que la supresión de estasrestricciones ayudaría a la reducción de la piratería. A día de hoy, 
laescasez de proyectos que han decidido simultanear el estreno en todos losmedios no permite realizar una evaluación exhaustiva de resultados.

Considerando estos apuntes iniciales, realizaremos un análisis de unsubsistema en el que la distribución y la exhibición de la película se realizana través de Internet. Desde este subsistema contemplaremos una primeramodalidad en la que este canal es dependiente de contenidoscomercializados previamente a través de las salas de cine y, una segunda,en la que Internet actúa como medio independiente para el que se creanproyectos específicos.

Internet como canal auxiliar de productos comercializados

En este subsistema, al que hemos denominado "digital", el motor sonlos generadores de contenidos (creador independiente o productoras) y loque varía con respecto a los anteriores subsistemas es, fundamentalmente,la intervención de nuevos elementos en la cadena de valor y la reducciónde la distancia entre el creador y el consumidor. Surge aquí una nuevafigura en el sector de la distribución: el proveedor de servicios, y un nuevo canal: Internet, a través del que se realiza la comunicación pública delproducto mercantil, la película.

En este nuevo ámbito contemplaremos dos mercados, de igual manera que lo hacía Dadek en el subsistema económico clásico, aunque no seránexactamente los mismos. Por un lado, al igual que en el ámbito clásico,tenemos el mercado de productos (entendiendo la película como artículo mercantil), en el que las partes contratantes son: la productora,distribuidora tradicional o el propio autor como oferentes del producto conrespecto al proveedor de servicios; y los usuarios como demandantes conrespecto al proveedor de servicios. Por su parte, el proveedor de serviciosactúa como demandante y oferente con respecto a la productora,distribuidora clásica o al creador y los usuarios, respectivamente.

En lo que se refiere al segundo mercado, al que Dadek denomina deexhibición en el subsistema clásico, aquí lo llamaremos de suscripción. Laspartes contratantes son el proveedor de servicios y los consumidores. Eneste caso, el objeto mercantil es la experimentación del flujo durante uncierto segmento de tiempo, siendo el más común un mes.

La relación contractual que se establece entre las productoras y elproveedor de servicios se desarrolla a través de la fórmula de compraventade licencias, que cada " $x$ " tiempo se renueva y renegocian, o lacesión de los derechos de explotación a cambio de un porcentaje de losbeneficios de las suscripciones. Normalmente, estos distribuidores onlineestán sujetos a normas que imponen las productoras y distribuidorastradicionales, tales como no distribuir determinados contenidos hastapasado un plazo de tiempo desde que salen a la venta, por ejemplo, enDVD.

Por otra parte, tal como ocurría entre cines y público en el subsistemaclásico a través de la cesión de una plaza, se establece una relacióncomercial entre los servidores de servicios o el propio creador y el público,que puede presentar dos formas diferentes dependiendo del mercado alque nos estemos refiriendo:

- Mercado de producto (Alquiler o venta). Cesión a través de Internetpor los sistemas de descarga o streaming de un título por undeterminado tiempo al espectador (una media de tres días) para suvisionado en caso de alquiler, y tiempo indefinido en caso decompra. El precio puede variar dependiendo de si los títulospertenecen al catálogo genérico, a una sección Premier o si sontítulos de estreno simultáneo en salas e Internet.

En este apartado podemos incluir los creadores de las películas quese financian a través de crowdfunding, puesto que la mayoría, como una de las recompensas más populares, ofrecen la posibilidad dedescarga del filme vía Internet a sus usuarios. La diferencia conrespecto al resto de productos es que, si la aportación la realiza elusuario durante la fase de desarrollo, tendrá que esperar muchotiempo para verla.

- Mercado de suscripción. Las formas más frecuentes son lassuscripciones mensuales y anuales. El usuario accede a todo 0 a lamayoría del catálogo a cambio de una cuota fija.

Pero Internet no sólo funciona como canal complementariodistribuyendo productos comercializados, sino que también actúa comomedio independiente para el que se crean contenidos específicos.

Internet como canal independiente

Esta modalidad engloba, fundamentalmente, proyectosindependientes con dificultad para acceder al circuito de explotacióncomercial. Se establece una relación directa entre el creador y elespectador y, del mismo modo que ocurría en la anterior modalidad, elproducto mercantil es la cesión de la película a través de Internet.

Cabe puntualizar que las plataformas de distribución ante las redesque desarrollan, tanto de cobertura como de contenidos, resultan una duracompetencia para el creador independiente, que en muchas ocasionesopta por la distribución gratuita a través de este canal.

Para diferenciarse de la competencia, hay algún proveedor decontenidos que gracias al respaldo de millones de suscriptores, ha optadopor centrarse en aportar contenido original. En este caso las productoraselaboran productos para ser explotados de manera específica en Interneta través de estos distribuidores online. La relación comercial que seestablece en este caso entre sus elementos integradores: productoras, proveedor de contenidos y usuarios se corresponde con la analizada en lamodalidad pretérita.

Si realizamos un breve repaso por los distintos subsistemaseconómicos, observamos que éste es el único que permite una relacióndirecta entre el creador y el consumidor, además de acoger proyectoscreativos que no cuentan con el respaldo de la industria.

\section{Conclusiones}


En este trabajo se han analizado las diferentes conceptualizaciones del cine digital. Los resultados de la investigación permiten concluir que las nuevas tecnologías y la convergencia de las mismas han dotado de inmejorables capacidades tanto al creativo para la realizacióndel producto como al espectador para su consumo.

Desde el punto de vista de la producción y postproducción, el realizador tiene al alcance de sus manos nuevas herramientas digitales que incrementan las posibilidades estéticas en el resultado final del producto película. Asimismo, los costes de la creación se reducen considerablementedebido a la desmaterialización en beneficio de las expresiones simbólicas.

En este nuevo panorama digital, la red permite que existan productos y servicios audiovisuales cuya cadena de valor reside íntegramente en Internet. Se reduce, por tanto, el coste en el almacenaje, que ya no necesita de espaciofísico y se posibilita la reutilización de los contenidos en otros soportes.

La distribución a través de Internet también presenta ventajas para el creador. La red eleva la posibilidad de alcanzarmás mercados y más personas. Al igual que en la creación y laproducción, también en la distribución disminuyen los costes. Las nuevas herramientas digitales permiten a cualquier creativo la posibilidad de distribuir su producto amuy bajo coste. La distancia entre los extremos de la cadena devalor (creativos y usuarios) se acorta, llegando a producirse incluso elcontacto directo y una posible colaboración entre ambos. Surgen nuevos modelos de negocio que dancabida a intermediarios ausentes en el sistema de distribucióntradicional, ubicados prácticamente todos ellos en la red (portales,buscadores, plataformas...). La distribución se diversifica ofertando los contenidos adaptados a diferentes canales y posibilitando llegar a audiencias heterogéneas.

La red funciona también como una plataforma rápida y eficaz para la promoción de los productos audiovisuales. Aparecen nuevas formas de financiación, como el crowdfunding, que además de para captar fondos, se consolida como una fórmula eficaz para establecer un vínculo con un público potencialmente interesado en un proyecto audiovisual antes de su realización.

Finalmente, se concluye que, con Internet surge una nueva rentabilidad económica para la industria cinematográfica. El comercio digital online basado en la descarga en línea (downloading) y en los servicios de suscripción, están convirtiendo a la red en unaplataforma digital de peso desde el punto de vista de la distribución y la exhibición para los contenidos audiovisuales.

\section{Bibliografía}

AIMC (2015), recuperado el 6 de diciembre de 2015, de, http://www.aimc.es/Las-salas-de-cine-hacia-la-plena.html

Cuevas, A. (1999): Economía cinematográfica. La producción y el comercio de películas. Madrid: Cía. Audiovisual Imaginógrafo.

Dadek, W. (1962): Economía cinematográfica. Madrid: ed. Rialp.

Darley, A. (2002): Cultura visual digital. Espectáculo y nuevos géneros en los medios de comunicación. Barcelona: Paidós.

Izquierdo, J. (2011): La digitalización en cine. Hacia el desarrollo de un modelo de negocio en Internet. Recuperado el 6 de diciembre de 2015, de,

http://www.aeic2012tarragona.org/comunicacions_cd/ok/344.pdf

Jacoste, J.G. (2004): El productor cinematográfico. Madrid: Síntesis.

Jenkins, H. (2008). Convergence Culture. La cultura de la convergencia de los medios de comunicación. Barcelona: Paidós

Manovich, L. (2005 [2001]): El lenguaje de los nuevos medios: la imagenen la era digital. Barcelona: Paidós.

Roig, A. (2009), "Cine en conexión”. Producción industrial y social en la era "cross-media”. Barcelona: UOCpress.

\section{Cómo citar este artículo en bibliografías - How to cite this article in bibliographies / references:}

LÓPEZ-GOLÁN, M. (2016): “La industria cinematográfica en la era digital. Diferentes conceptualizaciones y nuevas oportunidades para el creador". En Revista de la Asociación Española de Investigación de la Comunicación, vol. 3, número 5, pp. 82-87. 